\title{
Dental Precision Casting of Ti-29Nb-13Ta-4.6Zr Using Calcia Mold
}

\author{
Harumi Tsutsumi ${ }^{1}$, Mitsuo Niinomi ${ }^{1}$, Toshikazu Akahori ${ }^{1}$, Masaaki Nakai ${ }^{1}$, \\ Tsutomu Takeuchi ${ }^{2}$ and Shigeki Katsura ${ }^{3}$ \\ ${ }^{1}$ Institute for Materials Research, Tohoku University, Sendai 980-8577, Japan \\ ${ }^{2}$ Takeuchi Katan, Ltd., Toyohashi 441-8132, Japan \\ ${ }^{3}$ Yamahachi Dental Mfg., Co., Gamagori 443-0105, Japan
}

\begin{abstract}
The objective of this study is to develop a dental precision casting process for a beta-type titanium alloy, Ti-29Nb-13Ta-4.6Zr (TNTZ) alloy which has been developed for biomedical applications, using a mold made by electrically fused calcia particles. The effect of a combination of different sizes of calcia particles on the surface condition of the mold was investigated. In addition, to obtain a smooth surface, a cast TNTZ was made using a mold made using a mixture of calcia particles with a wax pattern conducted with calcia slurry coatings. Furthermore, surface reaction layer of the cast TNTZ was evaluated using an optical microscopy, a Vickers' hardness test and a X-ray diffractometry. The surface of the mold fabricated with a mixture of fine (diameter $<0.3 \mathrm{~mm}$ ) and coarse (diameter $=1-3 \mathrm{~mm}$ ) calcia particles is smooth and showed no cracks or defects. In addition, the surfaces of the cast TNTZ made using the duplex-coated wax pattern with the fine pure calcia slurry and crushed silica fiber-reinforced fine calcia slurry are very fine. Furthermore, the formation of the surface reaction layer on the cast TNTZ is remarkably inhibited. The results of this study should lead to enhancements in the creation of cast TNTZ for dental products. [doi:10.2320/matertrans.M2009139]
\end{abstract}

(Received April 16, 2009; Accepted May 26, 2009; Published July 8, 2009)

Keywords: titanium-based alloy, dental precision castings, calcia mold, $\alpha$-case, magnesiamold

\section{Introduction}

In dental field, an ion elution induced by corrosion from the surface of a dental products is a suspected cause of physical allergic reactions and/or damage to the dental product. Attempts have been made, therefore, to use Ti and its alloys in metallic prosthetic appliances due to their corrosion resistance and other excellent properties. ${ }^{1-3)}$ Especially, a Ti-29 mass\%Nb-13 mass\% Ta-4.6 mass\%Zr (TNTZ) alloy composed of non-toxic and non-allergenic elements such as $\mathrm{Nb}$, Ta and $\mathrm{Zr}$ has been predicted to be the nextgeneration biomaterial for prosthetic appliances and dental implants. ${ }^{4-7)}$ For example, the strength and hardness of TNTZ are sufficient for application in dental products. In addition, TNTZ doesn't damage an opposing dentition. The dental products are designed to fit diseased areas based on an individual patient's condition. Therefore, dental products are usually fabricated using a dental precision casting technique. In general, an alumina-based investment material is used for dental precision casting of precious dental alloys such as gold-based and Ag-Pd-Au-Cu-type alloys. However, since Ti and its alloys are very active at high temperatures, they easily react with the mold during casting. ${ }^{8)}$ A burned sticky layer and/or a surface-hardened layer, a so-called surface reaction layer, is formed on the surface of the cast. These surface reaction layers are believed to induce the deterioration of mechanical properties and to cause difficulty with the machine finish of the metallic prosthetic appliances. Therefore, a magnesia-based investment, which is more stable than an alumina-based investment at high temperatures, is also used for the dental precision casting of Ti and its alloys. ${ }^{9}$ The melting point of TNTZ, however, is around $2300 \mathrm{~K}$ and much higher than that of a conventional Ti alloy, Ti-6Al-4V ELI, because TNTZ contains a great deal of Ta and $\mathrm{Nb}$, of which the melting points are $3290 \mathrm{~K}$ and $5017 \mathrm{~K}$, respectively. ${ }^{10)}$ Since molten TNTZ is more active than Ti-6Al-4V ELI, it is impossible to inhibit the formation of the surface reaction layer on the TNTZ even if the magnesia-based investment is used for dental precision casting. Consequently, an additional machining process to remove the surface reaction layer from the TNTZ surface is necessary if the cast TNTZ is to be used in metallic prosthetic appliances. The development of mold materials that are stable at high temperatures for dental precision casting is, therefore, essential.

Researchers have focused on yttria, magnesia, zirconia and calcia particles as heat-resistant investments. ${ }^{8,11-13)}$ In particular, the authors have found that calcia-based investments inhibited the interface reaction between the surface of the cast alloy and the mold and also decreased the thickness of the reaction layer more than the conventional investment did in the pilot study. Calcia particles are among the most stable oxides in terms of the free energy of formation, so it is believed that the interface reaction will be inhibited. ${ }^{14,15)}$ Therefore, calcia particles are assumed to be suitable for the dental precision casting of TNTZ. However, the application of calcia particles to the investment for the dental precision casting of TNTZ has not been accomplished. Because of the hydration reactivity and high digestion ability of calcia particles, a mold made from these particles is easily cracked and is difficult to handle. Therefore, in this study, a dental precision casting process for TNTZ using a mold made by electrically fused calcia particles was investigated and developed.

\section{Materials and Methods}

\subsection{Cast material}

TNTZ disks with a diameter of $30 \mathrm{~mm}$ and a thickness of $13 \mathrm{~mm}$ were prepared from a hot forged TNTZ bar (Nb: 29.2 mass \%, Ta: 12.2 mass $\%, \mathrm{Zr}: 4.3$ mass $\%$, Fe: 0.05 mass $\%, \mathrm{~N}: 0.04$ mass $\%$, O: 0.01 mass $\%$ and Ti: balance) with a diameter of $30 \mathrm{~mm}$ and a length of $1000 \mathrm{~mm}$. 
Table 1 Chemical compositions of the electrically fused calcia particles (a) and the magnesia-based investment (b).

(a) Electrically fused calsia (mass\%)

\begin{tabular}{ccccc}
\hline $\mathrm{MgO}$ & $\mathrm{SiO}_{2}$ & $\mathrm{Al}_{2} \mathrm{O}_{3}$ & $\mathrm{Fe}_{2} \mathrm{O}_{3}$ & $\mathrm{CaO}$ \\
\hline 0.67 & 0.43 & 0.02 & 0.02 & bal. \\
\hline
\end{tabular}

(b) Magnesia-based investment (mass\%)

\begin{tabular}{ccccc}
\hline $\mathrm{SiO}_{2}$ & $\mathrm{Na}_{2} \mathrm{O}$ & $\mathrm{Fe}_{2} \mathrm{O}_{3}$ & $\mathrm{Al}_{2} \mathrm{O}_{3}$ & $\mathrm{MgO}$ \\
\hline 1.64 & 0.59 & 0.55 & 0.37 & bal. \\
\hline
\end{tabular}

\subsection{Wax pattern}

Wax patterns of a round bar with a diameter of $6 \mathrm{~mm}$ and a length of $50 \mathrm{~mm}$ were formed using a commercially available paraffin wax. Several wax patterns were coated with a calcia slurry to obtain a smooth casting surface as described in detail below. In addition, wax patterns of a cube with a side length of $15 \mathrm{~mm}$ were also formed to evaluate surface reaction layer of cast TNTZ. After a sprue and a sprue runner were set in upper side of each wax pattern, molds were fabricated as described in below.

\subsection{Mold}

Three different sizes of electrically fused calcia particles were used for investment. Their diameters were below $0.3 \mathrm{~mm}\left(\mathrm{C}_{1}\right), 0.3-1 \mathrm{~mm}\left(\mathrm{C}_{2}\right)$ and $1-3 \mathrm{~mm}\left(\mathrm{C}_{3}\right)$. The bonding agent of investment used in this study was a methanol solution with 7 mass $\%$ calcia chloride, $\mathrm{CaCl}_{2}$. A commercially available magnesia-based investment with alumina cement was also used as a control. The chemical composition of the electrically fused calcia particles and the magnesia investment is shown in Table 1.

Single $\mathrm{C}_{1}, \mathrm{C}_{2}$ and $\mathrm{C}_{3}$ particles or a mixture of two kinds of particles was used for investment. Mixture ratios of the electrically fused $\mathrm{C}_{1}, \mathrm{C}_{2}$ and $\mathrm{C}_{3}$ particles used to fabricate the molds, along with the abbreviations, are summarized in Table 2. Calcia particles were mixed with the bonding agent at a ratio of 93 (calcia particles): 7 (bonding agent) by weight and then invested in a mold frame with the wax pattern. A mold frame with a diameter of $50 \mathrm{~mm}$ and a length of $50 \mathrm{~mm}$ was used. The invested molds were held in a vacuum desiccator for $24 \mathrm{~h}$ at room temperature. Multiple baking processes were then carried out with the molds at an electric muffle furnace. A schematic image of the multiple baking processes for the calcia investment is shown in Fig. 1. After the baking processes were finished, the appearance and a cross-section of the mold were observed. From the results, the optimal mixture ratio of the electrically fused calcia particles was determined.

\subsection{Calcia slurry treatment}

To obtain a smooth casting surface, several wax patterns were coated with the calcia slurry. $\mathrm{A}_{1} \mathrm{C}_{3} 46$ (see Table 2) slurry was prepared by mixing $\mathrm{C}_{1} \mathrm{C}_{3} 46$ particles with the bonding agent at a ratio of $4: 1$ by weight. The wax patterns were immersed in $\mathrm{C}_{1} \mathrm{C}_{3} 46$ slurry 1 to 4 times. $\mathrm{C}_{1}$ particles were mixed with the bonding agent at a ratio of $4: 1$ by weight, and a $\mathrm{C}_{1}$ slurry was obtained (slurry $\mathrm{A}$ ). Then to reinforce the slurry A, 0.3 mass $\%$ silica fibers meshes
Table 2 Mixture ratios of electrically fused $\mathrm{C}_{1}, \mathrm{C}_{2}$ and $\mathrm{C}_{3}$ particles used to fabricate the molds, along with abbreviations.

$(\operatorname{mass} \%)$

\begin{tabular}{|c|c|c|c|c|c|c|}
\hline & \multicolumn{6}{|c|}{ Mold No. } \\
\hline & 1 & 2 & 3 & 4 & 5 & 6 \\
\hline $\mathrm{C}_{1}$ & 100 & - & - & 20 & 40 & 60 \\
\hline $\mathrm{C}_{2}$ & - & 100 & - & 80 & 60 & 40 \\
\hline $\mathrm{C}_{3}$ & - & - & 100 & - & - & - \\
\hline \multirow[t]{3}{*}{ Abbr. } & $\mathrm{C}_{1} 10$ & $\mathrm{C}_{2} 10$ & $\mathrm{C}_{3} 10$ & $\mathrm{C}_{1} \mathrm{C}_{2} 28$ & $\mathrm{C}_{1} \mathrm{C}_{2} 46$ & $\mathrm{C}_{1} \mathrm{C}_{2} 64$ \\
\hline & \multicolumn{6}{|c|}{ Mold No. } \\
\hline & 7 & 8 & 9 & 10 & 11 & \\
\hline $\mathrm{C}_{1}$ & 80 & 20 & 40 & 60 & 80 & \\
\hline $\mathrm{C}_{2}$ & 20 & - & - & - & - & \\
\hline $\mathrm{C}_{3}$ & - & 80 & 60 & 40 & 20 & \\
\hline Abbr. & $\mathrm{C}_{1} \mathrm{C}_{2} 82$ & $\mathrm{C}_{1} \mathrm{C}_{3} 28$ & $\mathrm{C}_{1} \mathrm{C}_{3} 46$ & $\mathrm{C}_{1} \mathrm{C}_{3} 64$ & $\mathrm{C}_{1} \mathrm{C}_{3} 82$ & \\
\hline
\end{tabular}

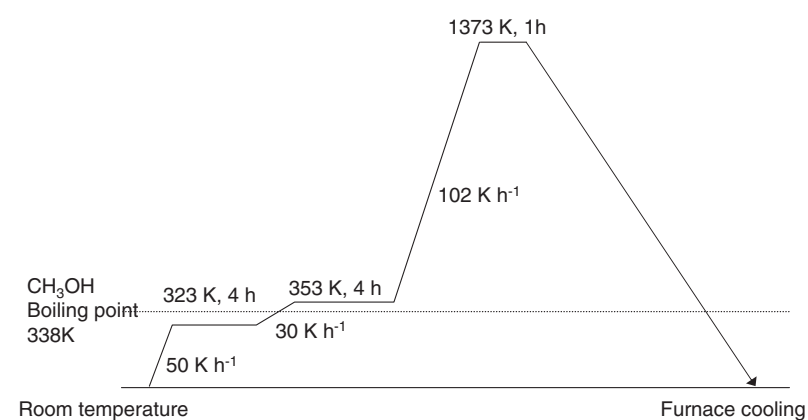

Fig. 1 Schematic image of the multiple baking processes for calcia investment.

Table 3 Combination of coating treatment of wax patterns.

\begin{tabular}{|c|c|c|c|c|c|c|}
\hline \multirow{2}{*}{$\begin{array}{c}\text { Coating } \\
\text { layer }\end{array}$} & \multicolumn{6}{|c|}{ Coating treatment No. } \\
\hline & 1 & 2 & 3 & 4 & 5 & 6 \\
\hline $1 \mathrm{st}$ & A & A & A & A & A & A \\
\hline 2nd & & $\mathrm{B}$ & $\mathrm{B}$ & A & A & A \\
\hline $3 \mathrm{rd}$ & - & 一 & B & 一 & B & B \\
\hline 4 th & - & - & 一 & - & - & B \\
\hline
\end{tabular}

A, Slurry A (20 mass $\% C_{1}$ particles); B, Slurry B (Slurry A + silica fiber)

$\left(5 \times 5 \mathrm{~mm}^{2}, 2 \mathrm{~mm}\right.$ in thickness) were mixed in slurry $\mathrm{A}$ (slurry B). Wax patterns were immersed in slurry A and/or slurry B several times. The combination of coating treatments of the wax patterns is shown in Table 3. To avoid mixing of the calcia layers, the wax patterns were coated at $1.2 \mathrm{ks}$ intervals. The coated wax patterns were then kept in a vacuum desiccator. Next, $\mathrm{C}_{1} \mathrm{C}_{3} 46$ particles with a bonding agent were invested in the mold frame with the wax pattern conducted with the calcia slurry coatings, as shown in Fig. 2. The invested molds were held in the vacuum desiccator for $24 \mathrm{~h}$ at room temperature, and multiple baking processes were then carried out in the manner described above. After the baking processes were finished, the appearance and the cross-section of the mold were observed.

\subsection{Casting}

Casting of the TNTZ was carried out using an argon pressure-type dental precision casting machine. The TNTZ 


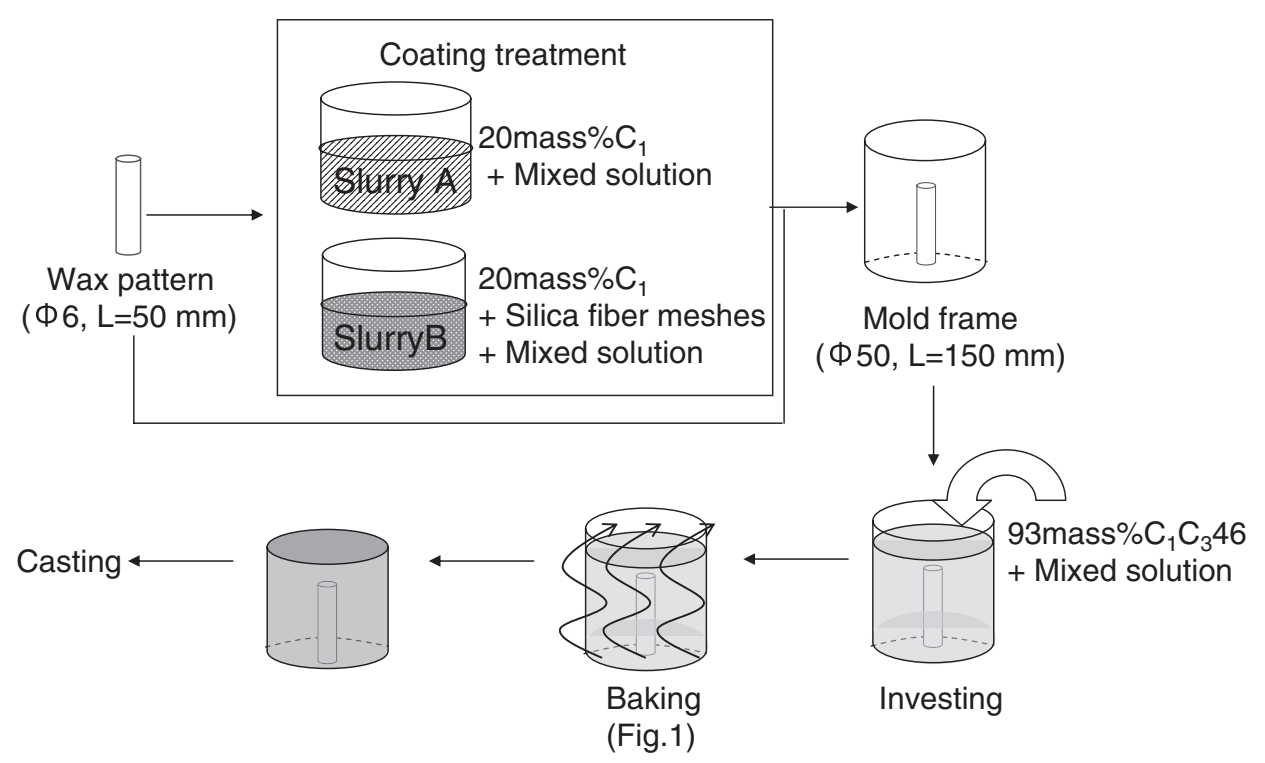

Fig. 2 Schematic image of the coating treatment of wax patterns.

disks were melted for $20 \mathrm{~s}$ under $10.2 \times 10^{-6} \mathrm{~Pa}$ by a $300-\mathrm{A}$ mono arc and then cast into a round bar under $0.7 \mathrm{~Pa}$ argon gas pressure using the calcia or the magnesia mold as described above. From the surface appearance, the optimal fabricating condition of the calcia mold was determined.

\subsection{Observation of microstructure and evaluation of surface reaction layer of cast TNTZ}

Observation of microstructure and evaluation of surface reaction layer of cast TNTZ were carried out using an optical microscopy (OM), a Vickers hardness test and a X-ray diffractometry (XRD). The cast TNTZ disks were mechanically cut from the center of the cast TNTZ round bar. The cast TNTZ disks were polished with 320-1500 grid SiC papers in water, followed by buffering with $0.3-\mu \mathrm{m} \mathrm{Al}_{2} \mathrm{O}_{3}$. The microstructure and surface reaction layer of cast TNTZ disks were observed using the OM. The Vickers hardness (Hv) of the cast TNTZ disks was measured using a $\mathrm{Hv}$ tester in air at room temperature under a constant loading condition (load: $4.9 \mathrm{~N}$, holding time $15 \mathrm{~s}$ ). The Hv was measured from the surface to inside at intervals of $25 \mu \mathrm{m}$ in a zigzag manner. In addition, phase identification of cast TNTZ disk was performed using a XRD. From these results, the thickness and the hardness of the surface reaction layer of the cast TNTZ were determined.

\subsection{Casting of simulated TNTZ dental crown}

A simulated dental crown was fabricated using the optimal mold-making condition of the calcia particles in the manner described above.

\section{Results and Discussion}

\subsection{Effect of the mixture ratio of fine and coarse particles on the cracking of the mold}

A number of cracks are observed on the surface of the mold fabricated with $\mathrm{C}_{1} 10$ particles, as shown in Fig. 3 . Just as it is generally difficult to fabricate a green mold with

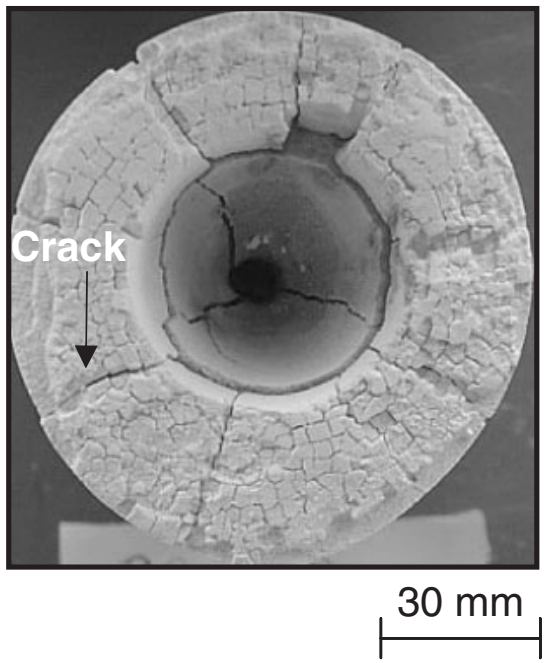

Fig. 3 Photograph of the calcia mold fabricated with $C_{1} 10$ particles.

$\mathrm{C}_{2} 10$ or $\mathrm{C}_{3} 10$ particles, it is difficult to form a mold using $\mathrm{C}_{1} 10, \mathrm{C}_{2} 10$ or $\mathrm{C}_{3} 10$ particles.

Photographs of cross-sections of the calcia molds fabricated using the various mixing ratios of $\mathrm{C}_{1} \mathrm{C}_{2}$ or $\mathrm{C}_{1} \mathrm{C}_{3}$ particles are shown in Fig. 4. When a mold is fabricated with $\mathrm{C}_{1} \mathrm{C}_{2} 82$ or $\mathrm{C}_{1} \mathrm{C}_{3} 82$ particles, many deep cracks are observed on the surface. The number of surface cracks decrease with an increase in the ratio of $\mathrm{C}_{3}$ and $\mathrm{C}_{2}$ particles. However, when the mold is fabricated with $\mathrm{C}_{1} \mathrm{C}_{2} 28$ or $\mathrm{C}_{1} \mathrm{C}_{3} 28$ particles, the surface of the mold is very rough and can not be used as a mold.

Calcia particles expand during the drying treatment. When a mold is fabricated with high-density small calcia particles such as $\mathrm{C}_{1} 10, \mathrm{C}_{1} \mathrm{C}_{2} 82$ and $\mathrm{C}_{1} \mathrm{C}_{3} 82$ particles, the mold cracks because there is not enough space for the particles to expand completely. On the other hand, when a mold is fabricated with a mixture of particles of different sizes, $\mathrm{C}_{1}$ particles exist in the spaces between the $\mathrm{C}_{2}$ and $\mathrm{C}_{3}$ particles. Therefore, the $C_{1}$ particles are able to expand completely, 


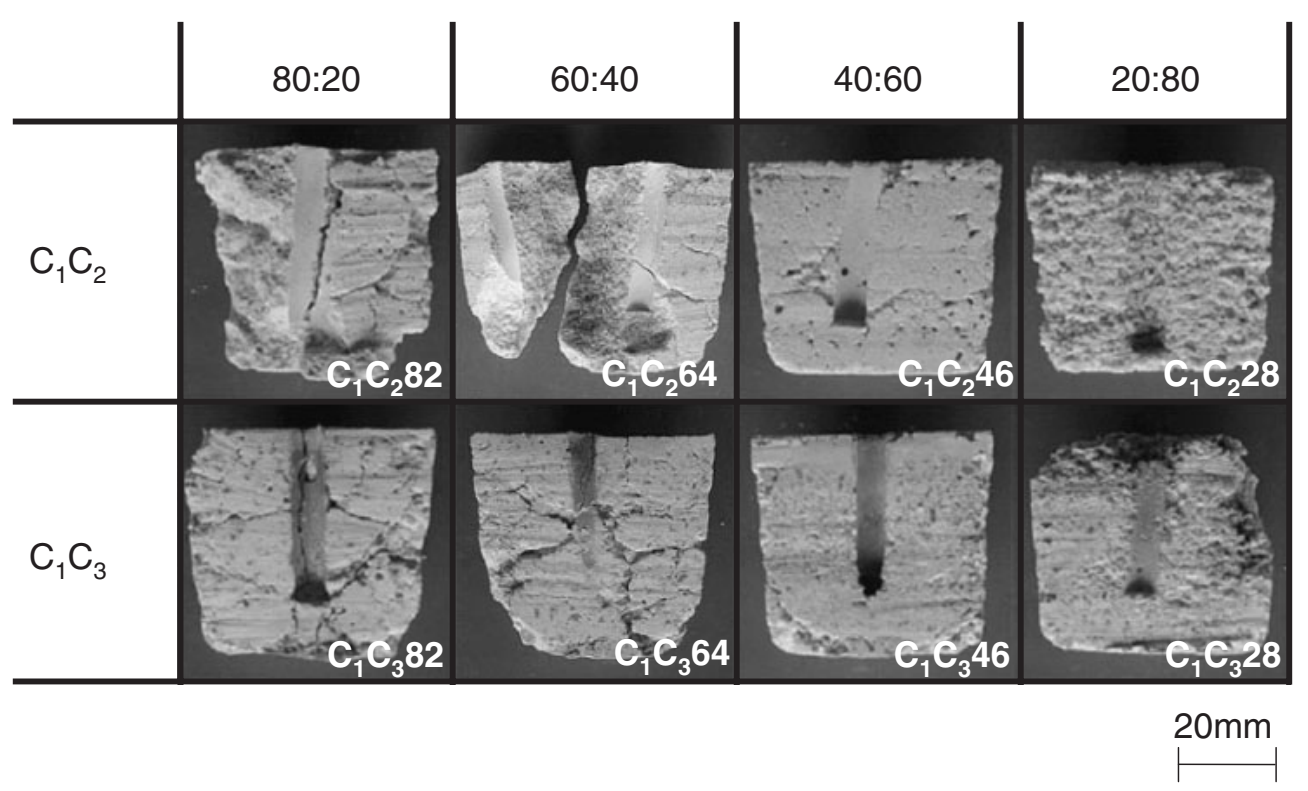

Fig. 4 Photographs of the cross-sections of each calcia mold fabricated with various mixture ratios of $\mathrm{C}_{1} \mathrm{C}_{2}$ or $\mathrm{C}_{1} \mathrm{C}_{3}$ particles.

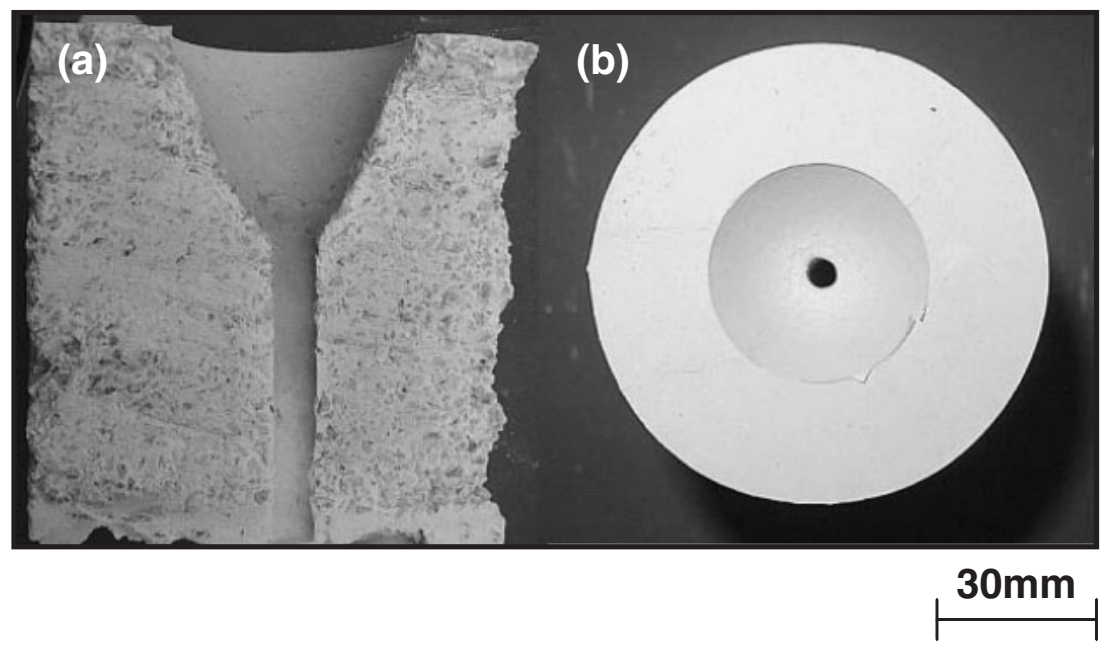

Fig. 5 Photographs of the cross-section (a) and the appearance (b) of the calcia mold fabricated by $\mathrm{C}_{1} \mathrm{C}_{3} 46$ particles.

and a smooth mold surface with no cracks is obtained. The mold fabricated with $\mathrm{C}_{1} \mathrm{C}_{3} 46$ particles have a superior mold surface with almost no cracks, as shown in Fig. 5. Apparently, crack initiation is inhibited because the expansion of the $\mathrm{C}_{1}$ particles is properly absorbed with the addition of the $60 \% \mathrm{C}_{3}$ particles. However, when the mold is fabricated by $\mathrm{C}_{1} \mathrm{C}_{2} 28$ or $\mathrm{C}_{1} \mathrm{C}_{2} 28$ particles, the number of $\mathrm{C}_{1}$ particles is insufficient to fill up the space between the $C_{2}$ and the $C_{3}$ particles. As a result, the surface of the mold is very rough, rendering the mold unusable.

In this study, a mold fabricated by $\mathrm{C}_{1} \mathrm{C}_{3} 46$ particles is applied to TNTZ casting since the smoothest surface is obtained from this mold, as described above.

Photographs of the cast TNTZ made with the molds fabricated from $\mathrm{C}_{1} 10$ (Fig. 6(a)) and $\mathrm{C}_{1} \mathrm{C}_{3} 46$ particles (Fig. 6(b)) are shown in Fig. 6. The surface of the cast TNTZ made with the mold fabricated from $\mathrm{C}_{1} \mathrm{C}_{3} 46$ particles is smoother than that of the cast TNTZ fabricated with $\mathrm{C}_{1} 10$ particles. However, small projections are observed on both surfaces of the cast TNTZ. The surface roughness is particularly great in the bottom part of the specimen. The projections are likely formed by bubbles which could not escape during investment or penetration of the molten metal into gap between the particles of the mold. In order to inhibit the formation of projection on the surface of the cast TNTZ, several methods of coating of the wax pattern were tried as described below.

\subsection{Effect of the calcia coating of the wax pattern on the appearance of the casting}

Figure 7 shows the appearance of the cast TNTZ using the wax pattern with 1,2 and 4 coatings of the $C_{1} C_{3} 46$ slurry. Fins are observed on the cast TNTZ surfaces. Penetration obviously increases with the coating time. However, the surface condition of the cast TNTZ without penetration is much better than that of the cast TNTZ using the wax pattern without coating, as stated above.

In order to avoid penetration of the end of the cast TNTZ and to modify the surface condition, the coating layer of the wax pattern is reinforced with crushed silica fibers meshes. 

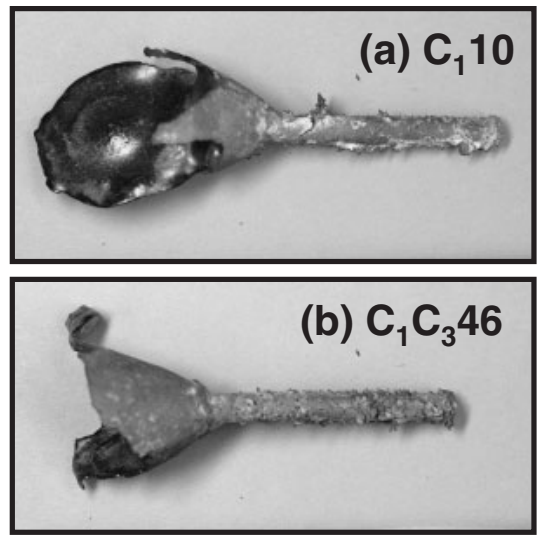

$20 \mathrm{~mm}$

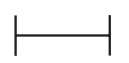

Fig. 6 Photographs of the cast TNTZ using the calcia mold fabricated by $\mathrm{C}_{1} 10$ (a) and $\mathrm{C}_{1} \mathrm{C}_{3} 46$ (b) particles.
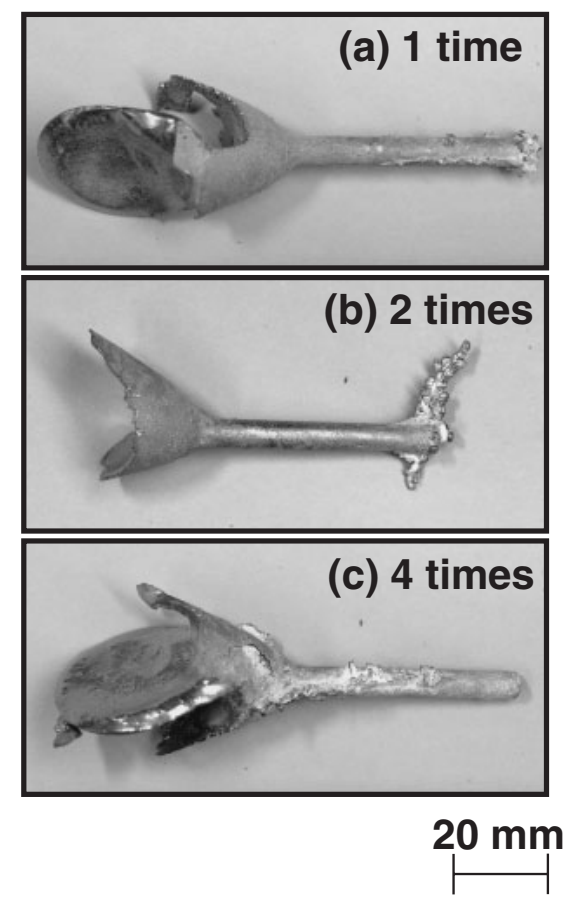

Fig. 7 Photographs of the cast TNTZ using the wax patterns conducted with 1 (a), 2 (b) and 4 (c) coatings of the $C_{1} C_{3} 46$ slurry.

Table 4 shows the presence of cracks in the mold and defects in the cast TNTZ when the wax pattern conducted with multiple coatings of slurry A and/or slurry B is used. When the number of coating layers of the wax pattern is more than 3 , i.e., coating treatments Nos. 3, 5 and 6, many cracks are observed on the surface of the mold. It is likely that the thickness of the coating layer increases with an increase in the number of coating treatments. Therefore, the expansion of $\mathrm{C}_{1}$ particles contained in slurry $\mathrm{A}$ and $\mathrm{B}$ induces cracks during the drying process, as described above. On the other hand, when the coating layer is a single or double layer, i.e., coating treatments Nos. 1, 2 and 4, no cracks are observed on the surface of the mold. The smoothest surface is obtained from the mold using the wax pattern conducted with a duplex
Table 4 Presence of cracks in the coating layer of the wax pattern conducted with multiple coating treatments (A) and a cast defect of TNTZ cast using the treatments (B).

\begin{tabular}{lcccccc}
\hline \multicolumn{1}{c}{ Coating } & \multicolumn{7}{c}{ Coating treatment No. } \\
\multicolumn{1}{c}{ layer } & 1 & 2 & 3 & 4 & 5 & 6 \\
\hline $\begin{array}{l}\text { (A) Crack } \\
\text { of coating } \\
\text { layer }\end{array}$ & $\times$ & $\times$ & 0 & $\times$ & 0 & 0 \\
\hline $\begin{array}{l}\text { (B) Cast } \\
\text { defect }\end{array}$ & 0 & $\times$ & - & 0 & - & - \\
\hline
\end{tabular}

$\bigcirc$ : Exist, $\times$ : Not exist, —: Not tried

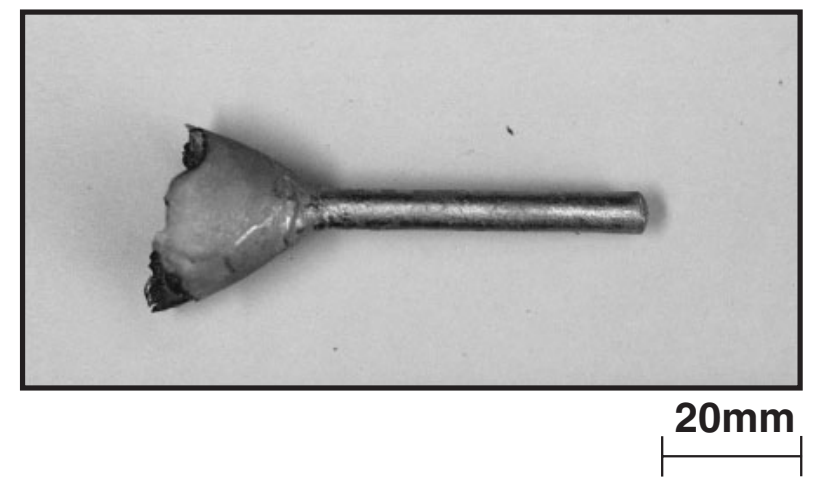

Fig. 8 Photograph of the cast TNTZ using a wax pattern conducted with a duplex coating of slurry A and slurry B (coating treatment No. 2).

coating of slurry A and slurry B, i.e., coating treatment No. 2. However, in spite of the coating layer, many defects are observed on the surface of the TNTZ cast when the wax pattern conducted with only slurry A is used. Because of the insufficient strength of the coating layer, one part of the coating layer is broken, and penetration defects are formed during the casting.

A photograph of the cast TNTZ made using the wax pattern conducted with a duplex coating of slurry A and slurry B is shown in Fig. 8. In this case, even though sandblasting treatment is not carried out, the surface condition of the specimen is very smooth and without penetration. The optimal calcia mold for the TNTZ casting is fabricated by $\mathrm{C}_{1} \mathrm{C}_{3} 46$ particles using the wax pattern conducted with a duplex coating of slurry A and slurry B (hereafter called the duplex calcia casting method).

\subsection{Surface reaction layer of the cast TNTZ made by the duplex calcia casting method}

Figure 9 shows the optical micrographs of cross sections of the cast TNTZ using the duplex calcia casting methods (hereafter called $\mathrm{TNTZ}_{\text {calcia }}$ ) and the cast $\mathrm{TNTZ}$ using magnesia-based investment (hereafter called $\mathrm{TNTZ}_{\text {magnesia }}$ ). Dendritic structure is observed on both the $\mathrm{TNTZ}_{\text {calcia }}$ and the $\mathrm{TNTZ}_{\text {magnesia. }}$ Though surface reaction layer is also observed on both the $\mathrm{TNTZ}_{\text {calcia }}$ and the $\mathrm{TNTZ}_{\text {magnesia }}$, thickness of the surface reaction layer of the $\mathrm{TNTZ}_{\text {calcia }}$ is thinner than that of the surface reaction layer of the TNTZ $Z_{\text {magensia. }}$ Figure 10 shows the $\mathrm{Hv}$ distribution of the $\mathrm{TNTZ}_{\text {calcia }}$ as a function of the distance from the surface of specimens, along with the $\mathrm{Hv}$ data obtained from the $\mathrm{TNTZ}$ magnesia. Due to the 

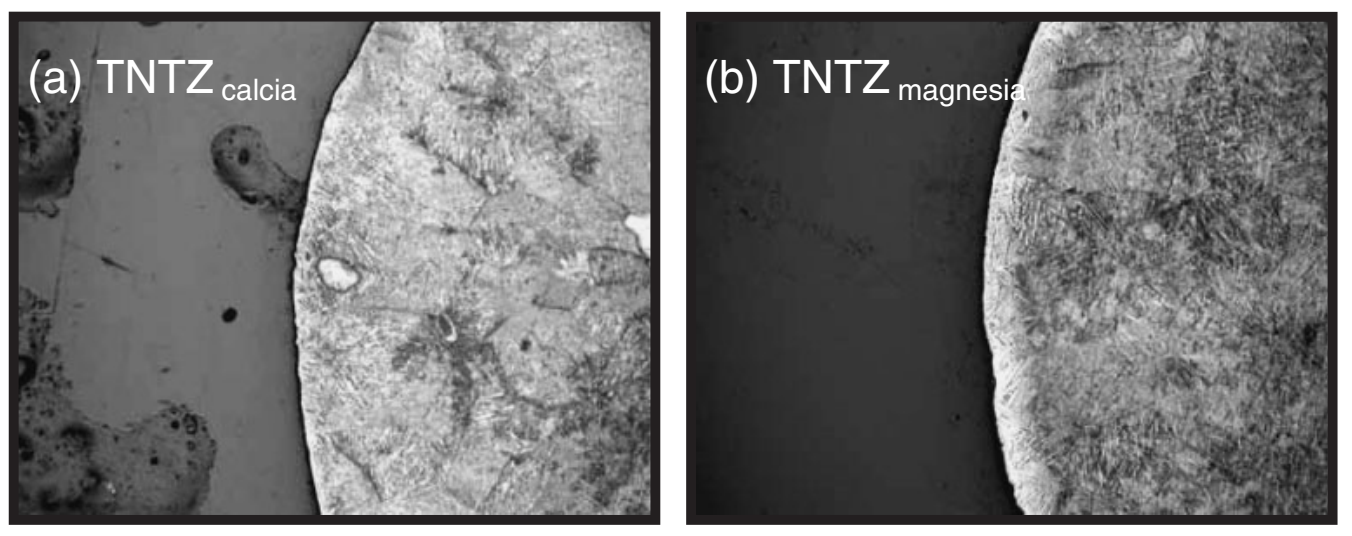

$100 \mu \mathrm{m}$

Fig. 9 Optical micrographs of cross sections of specimens of the $\mathrm{TNTZ}_{\text {calcia }}$ (a) and the $\mathrm{TNTZ}_{\text {magnesia }}$ (b).

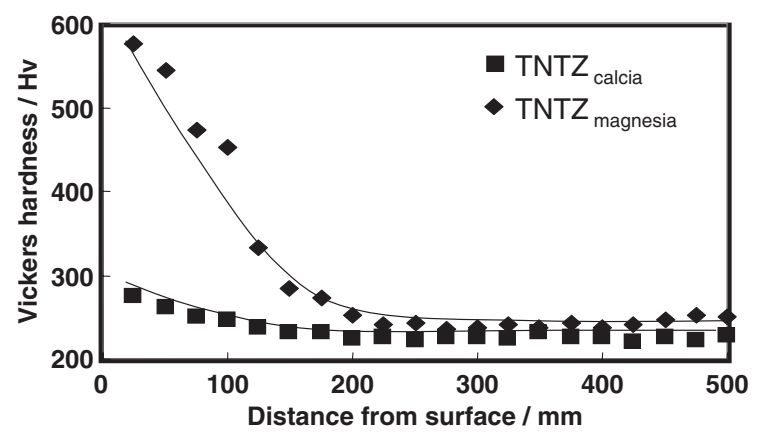

Fig. $10 \mathrm{Hv}$ of the $\mathrm{TNTZ}_{\text {calcia }}$ and the TNTZ $\mathrm{Z}_{\text {magnesia }}$ as a function of the distance from the surface of the specimen.

formation of surface reaction layer, a greater $\mathrm{Hv}$ is found near to the specimen surface of the $\mathrm{TNTZ}_{\text {calcia }}$ and the $\mathrm{TNTZ}_{\text {magnesia. }}$. However, the Hv near the surface of the $\mathrm{TNTZ}_{\text {calcia }}$ is much lower than that of the $\mathrm{TNTZ}_{\text {magensia }}$. Thickness of the surface reaction layer of the $\mathrm{TNTZ}_{\text {calcia }}$ is estimated at $120 \mu \mathrm{m}$, while that of the $\mathrm{TNTZ}_{\text {magnesia }}$ was estimated at $200 \mu \mathrm{m}$. XRD patterns of cube specimens of the $\mathrm{TNTZ}_{\text {calcia }}$ and the $\mathrm{TNTZ}_{\text {magensia }}$ as a function of distance from the specimens surface are shown in Fig. 11. Only $\beta$ phase peaks are detected from the surface to $160 \mu \mathrm{m}$ of the $\mathrm{TNTZ}_{\text {calcia }}$. On the other hand, not only $\beta$ phase peaks but also $\alpha$ phase peaks are detected from the surface to $160 \mu \mathrm{m}$ of the $\mathrm{TNTZ}_{\text {magnesia }}$.

In general, oxygen is generated from the mold material during casting, and it is diffused into the cast material. In this research, since oxygen works as $\alpha$ stabilizer, $\alpha$ phase is precipitated and surface reaction layer, so-called $\alpha$-case, is formed on the surface of the cast TNTZ. Because of the $\alpha$-case, hardness of the surface of the $\mathrm{TNTZ}_{\text {calcia }}$ and the TNTZ $Z_{\text {magnesia }}$ are increased as shown above. On the other hand, thickness of $\alpha$-case of the $\mathrm{TNTZ}_{\text {calcia }}$ is thinner than that of $\mathrm{TNTZ}_{\text {magnesia. In }}$ addition, $\mathrm{Hv}$ of the $\alpha$-case of $\mathrm{TNTZ}_{\text {calcia }}$ is lower than that of $\mathrm{TNTZ}_{\text {magnesia. The free }}$ energy of formation of calcia particles is lower than that of titanium oxide (titania) at TNTZ melting point (around $2300 \mathrm{~K})$. Therefore calcia particles are stable during the casting. On the other hand, the free energy of formation of magnesia particles is higher than that of titanium oxide at over $1700 \mathrm{~K}$. Since magnesia particles are more unstable than that of titania, magnesia particles are reduced and generate oxygen. It is considered amount of generated oxygen from the calcia mold are much lower than that of generated oxygen from the magnesia mold during the casting. Therefore, oxygen diffusion into the $\mathrm{TNTZ}_{\text {calcia }}$ is inhibited, as a result, formation of $\alpha$-case of $\mathrm{TNTZ}_{\text {calcia }}$ is also inhibited.

\subsection{Metallic prosthetic appliances made by the duplex calcia casting method}

TNTZ is applied to make one example of a metallic prosthetic appliance, a crown, using the calcia duplex casting method. A photograph of the crown made by the calcia duplex casting method is shown in Fig. 12. The TNTZ crown is successfully fabricated using the calcia duplex casting method.

\section{Conclusions}

In this study, a dental precision casting process for TNTZ using a mold made by electrically fused calcia particles was developed. The following results were obtained.

(1) The surface of the mold fabricated by a mixture of $20 \%$ fine (diameter $<0.3 \mathrm{~mm}$ ) and $80 \%$ coarse (diameter $=$ $1-3 \mathrm{~mm}$ ) calcia particles is smooth and showed no cracks or defects.

(2) The surfaces of the cast TNTZ using the calcia duplex casting method are very fine.

(3) The formation of the $\alpha$-case on the cast TNTZ using the calcia duplex casting method is remarkably inhibited.

(4) A metallic prosthetic appliance, a crown, of cast TNTZ is successfully fabricated using the calcia duplex casting method.

The results of this study should lead to enhancements in the creation of cast TNTZ for dental products.

\section{Acknowledgements}

This work was supported in part by a Grant-in-Aid for Young Scientists (21760549), MEXT (Tokyo, Japan); the 


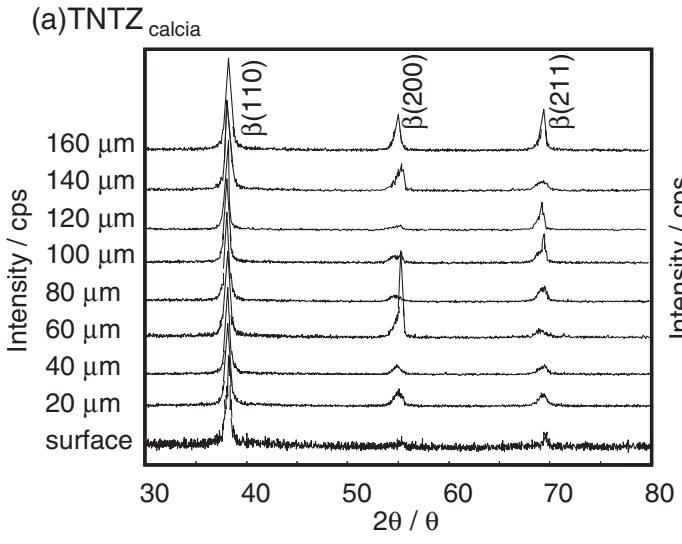

Fig. 11 XRD patterns of the $\mathrm{TNTZ}_{\text {calcia }}$ (a) and the $\mathrm{TNTZ}_{\text {magenesia }}$ (b) as a function of distance from the specimen surface.

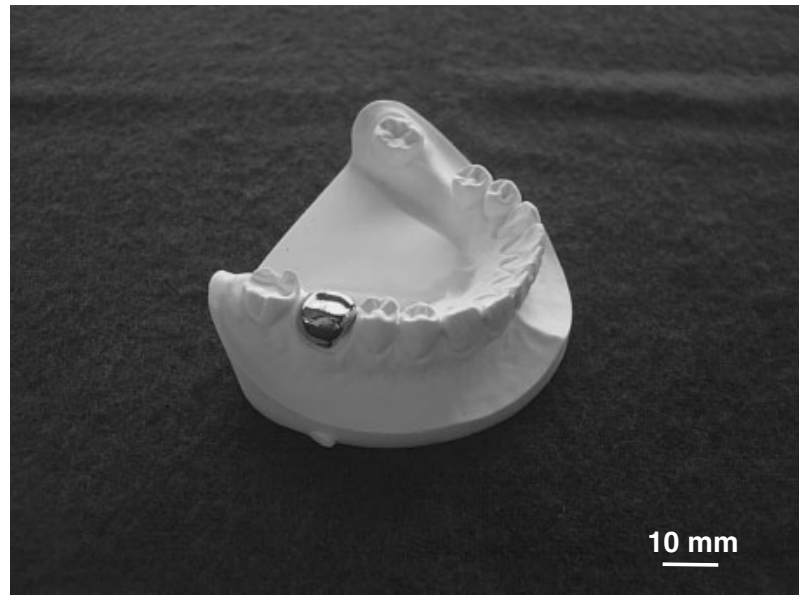

Fig. 12 Photograph of a dental crown of a TNTZ cast made by the duplex calcia coating method.

Global COE Materials Integration Program (International Center of Education and Research), Tohoku University; MEXT (Tokyo, Japan); R\&D Institute of Metals and Composites for Future Industries (Tokyo, Japan); Interuniversity Cooperative Research Program of the Advanced Research Center of Metallic Glasses, Institute for Materials Research, Tohoku University (Sendai, Japan); Interuniversity Cooperative Research Program of the Institute for Materials Research, Tohoku University (Sendai, Japan); and the Light Metal Educational Foundation (Osaka, Japan); the project (b) TNTZ magnesia

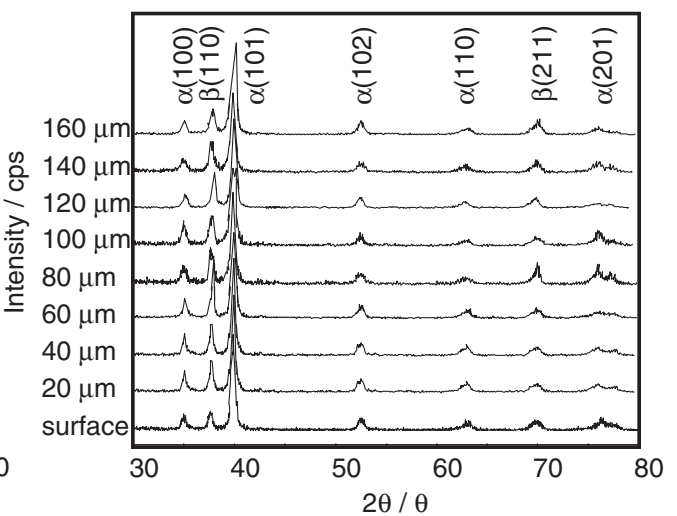

between Tohoku University and Kyusyu University on "Highly-functional Interface Science: Innovation of Biomaterials with Highly-functional Interface to Host and Parasite", MEXT (Tokyo, Japan).

\section{REFERENCES}

1) K. Ida and I. Miura: Application of Titanium for Denture Field (1988) 12-14.

2) Y. Okazaki, A. Ito, T. Tateishi and Y. Ito: J. Japan Inst. Metals 57 (1993) 332-337.

3) T. Hanwa: J. Jpn. Soc. Biomat. 23 (2005) 83-90.

4) M. Niinomi, T. Hattori, K. Morikawa, T. Kasuga, A. Suzuki, H. Fukui and S. Niwa: Mater. Trans. 43 (2002) 2970-2977.

5) M. Niinomi: Biomaterials 24 (2003) 2673-2683.

6) Y. L. Hao, M. Niinomi, D. Kuroda, K. Fukunaga, R. Yang and A. Suzuki: Metall. Mater. Trans. A 34 (2003) 1007.

7) S. J. Li, M. Niinomi, T. Akahori, T. Kasuga, R. Yang and Y. L. Hao: Biomaterials 25 (2004) 3341-3349.

8) Y. Tamaoki and T. Miyazaki: Prosthodont. Res. Pract. 42 (1998) 528-534.

9) N. Tsugaya, S. Suzuki, K. Iida, M. Nakamura and T. Kamimura: J. J. Dent. Mater. 4 (1985) 344-349.

10) M. Niinomi, T. Akahori, T. Manabe, T. Takeuchi, S. Katsura, H. Fukui and A. Suzuki: Testu-to-Hagane 90 (2004) 154-161.

11) F. Watari, F. Nishimura, H. Nakamura, R. Fukumoto and N. Morita: J. J. Dent. Mater. 9 (1990) 734-740.

12) S. Motoi: Sekko to Sekkai 154 (1978) 123-127.

13) K. Hamano: Sekko to Sekkai 157 (1978) 244-253.

14) A. Sato, N. Matsumoto, Y. Yoneda, T. Takahashi and H. Iwanabe: Imono 62 (1990) 732-737.

15) M. G. Kim, S. K. Kim and Y. J. Kim: Mater. Trans. 43 (2002) 745750 . 